Plant Molecular Biology 26: 1019, 1994.

(C) 1994 Kluwer Academic Publishers. Printed in Belgium.

Erratum

\title{
Molecular cloning and characterization of a legumin-like storage protein cDNA of Douglas fir seeds
}

Isabel Leal and Santosh Misra*

Department of Biochemistry and Microbiology, University of Victoria, Victoria, British Columbia V8W 3P6, Canada (* author for correspondence)

Plant Molecular Biology 21: 709-715, 1993.

The sequence of $11 \mathrm{~S}$ legumin-like cDNA published in this paper has been found to contain errors. The correct sequence can be found in the Genbank databank under the accession number L07484. The most notable change is in the processing cleavage site ASN/ASP rather than ASN/GLY which is the consensus site for angiosperm legumins. 